\title{
Monitoring of Heart Ischemia in Blood Serum
}

\author{
Vladimíra Tomečková1*, Vladimír Komanickýn ${ }^{2}$, Mohammad Kakoush¹, Kristína Krajčíková1, \\ Gabriela Glinská1, Monika Široká1, Lýdia Pundová ${ }^{3}$, Tomáš Samuely², Dominika Hložná2, \\ Dmytro Lotnyk ${ }^{2}$
}

\begin{abstract}
${ }^{1}$ Department of Medical and Clinical Biochemistry, Faculty of Medicine, Pavol Jozef Šafárik University in Košice, Slovak Republic
${ }^{2}$ Institute of Physics, Faculty of Science, Pavol Jozef Šafárik University in Košice, Slovak Republic

${ }^{3} 1$ st Department of Internal Medicine, Faculty of Medicine, Pavol Jozef Šafárik University in Košice, Slovak Republic

Email: ^vladimira.tomeckova@upjs.sk, mohamad_734@yahoo.com, kristina.ugrayova@student.upjs.sk, glinska.gabriela@gmail.com, moni.siroka@gmail.com, vladimir.komanicky@upjs.sk, tomas.samuely@upjs.sk, dominika.hlozna@student.upjs.sk, dmytro.lotnyk@student.upjs.sk, lydia.pundova@upjs.sk
\end{abstract}

How to cite this paper: Tomečková, V., Komanický, V., Kakoush, M., Krajčíková, K., Glinská, G., Široká, M., Pundová, L., Samuely, T., Hložná, D. and Lotnyk, D. (2016) Monitoring of Heart Ischemia in Blood Serum. Spectral Analysis Reviews, 4, $11-22$.

http://dx.doi.org/10.4236/sar.2016.42002

Received: July 22, 2016

Accepted: August 30, 2016

Published: September 2, 2016

Copyright $\odot 2016$ by authors and Scientific Research Publishing Inc. This work is licensed under the Creative Commons Attribution International License (CC BY 4.0).

http://creativecommons.org/licenses/by/4.0/

\begin{abstract}
Our aim was to study the selected cases of the patients with ischemic heart disease and to analyze the structure of blood serum of patients in comparison with control serum of healthy subjects by methods: synchronous fluorescence fingerprint and atomic force microscopy that are still not used in clinical practice. Our results of fluorescence analysis showed that blood serum of all patients with ischemic heart disease decreased intensity of fluorescence in comparison with control blood serum. Endogenous fluorescence of synchronous fluorescence fingerprint of blood serum of patients with unstable angina pectoris state after non ST elevation myocardial infarction; angina pectoris and arterial hypertension 3 was similar, but atomic force microscopy revealed differences in the structure of blood serum of patients with the angina pectoris. Blood serum of patients with angina pectoris exhibited disappearance of fluorescence peak with maximum fluorescence and showed lower fluorescence intensity than control blood serum and blood serum of patients with arterial hypertension 2. Profiles of synchronous fluorescence fingerprint of blood serum of patients with arterial hypertension stage 2 showed formation of the new fluorescent peak with maximum fluorescence, similar shape of synchronous fluorescence fingerprint and higher fluorescence intensity than blood serum of healthy subjects. Blood serum sensitively revealed changes in the body by using untraditional novel techniques which enable the analysis of the mixture of blood serum and might be a new possibility in study of heart ischemia diseases.
\end{abstract}

\section{Keywords}

Blood Serum, Fluorescence Analysis, Atomic Force Microscopy, Ischemic Heart

Disease 


\section{Introduction}

Myocardial ischemia can lead to damage of the heart muscle, reducing its ability to pump efficiently and lead to the serious abnormal heart rhythms. Conditions that can cause myocardial ischemia include coronary artery disease (atherosclerosis), which can lead to a heart attack. According to global, regional and national incidence (2015), about 8.6 million myocardial infarctions (MI) occurred in 2013. More than 4 million had a non ST elevation myocardial infarction (NSTEMI) and more than 3 million people had an ST elevation MI [1]. STEMIs occur about twice as often in men as women [2]. The mitochondria of cardiomyocytes produce energy in the form of ATP by oxidative phosphorylation of glucose and fatty acids [3]. The patients with myocardial ischemia exhibited higher serum levels of glucose and lactate and concomitant lower serum levels of fatty acids [4]. Another phenomenon of acute myocardial ischemia is higher blood serum level of glycine, tyrosine and phenylalanine in swine and humans [4]. Phenylalanine is a substrate for tyrosine which is key precursor for biosynthesis of catecholamines which regulate immune and inflammatory responses [5]. Increased blood serum phenylalanine is also a manifestation of the inflammatory states [6]. The primary response to counter-act this effect and maintain physiological homeostasis is increasing serum level of $\mathrm{N}$-acetyl glycoproteins due to their anti-inflammatory and antioxidant activity [7] [8]. On the other hand, glycine has been reported to be elevated in heart failure patients [9] and glycine treatment in ischemia-reperfusion injury rats reduced the infarct size by $21 \%$ compared to vehicle-treated AMI rats [10]. The increased serum level of glycine relates to an inhibition of proteolysis of skeletal muscle protein and a reparation of myocardium. Ischemia is a restriction in blood supply to tissues, leading to functional changes generally caused by problems with blood vessels, causing a lack of oxygen and glucose needed for cellular metabolism to keep tissue alive. The hypoxia produces the limited aerobic glycolysis leading to a switch in energy supply from aerobic metabolism to anaerobic metabolism. The alternative energy substrates, such as amino acids increases and contribute to acidosis by anaerobic oxidation and decrease blood serum concentration of amino acids [11]. The low blood serum concentration of amino acids results in protein-energy wasting, inflammation and oxidative stress [7] [12]. Oxidative stress is the state of increased production of reactive oxygen species (ROS) which lead to oxidative modification of proteins and lipoproteins [13]. It is a potential hallmark of ischemia diseases. These modified species function atypically and often lead to immune reactions and inflammations [14]. Inflammatory leukocytes infiltration early after ischemia is an important trigger for ischemia-induced angiogenesis. Inflammatory cells can release various angiogenic cytokines including vascular endothelial growth factor (VEGF) and other various angiogenic growth factors, cytokines, bone marrow-derived progenitor cells, extracellular matrix, and vasoactive substance. It is important to understand and to differentiate the normal physiological variations of ischemia and angiogenesis and to differentiate from the pathological changes. This experimental work studied ischemic heart diseases in blood serum of patients with various representative cases of cardiovascular disease. This work can contribute to 
study an early detection of ischemic heart disease by using untraditional methods of fluorescence spectroscopy and atomic force microscopy, which are not used in clinical practice.

\section{Material and Methods}

\subsection{Experimental}

Blood of patients with ischemic heart (cases) was collected by cardiologist MUDr. Lýdia Pundová, CSc. in vacutainer tube in Cardiology department, Louis Pasteur University Hospital in Košice. After the collection, blood serum in the tube was standing at room temperature $\left(20^{\circ} \mathrm{C}-25^{\circ} \mathrm{C}\right)$. The collected blood of healthy and experimental subjects was centrifuged for five minutes at $4500 \mathrm{rpm}$. All collected samples of blood serum of patients (representative selected cases) and healthy subjects were frozen and stored at $\mathrm{t}$ $=-20^{\circ} \mathrm{C}$. Representative patients with heart ischemia disease were selected (case 1) with unstable angina pectoris with state after non ST elevation myocardial infarction (NSTEMI). Case 2 patients $(n=10)$ exhibited ischemia heart disease with syndrome angina pectoris; case 3 patients $(n=10)$ suffered with arterial hypertension stage 3; case 4 patients $(n=10)$ showed high risk of arterial hypertension stage 2 and case 5 patients $(n=10)$ exhibited ischemia heart disease with arterial hypertension degree $2 /$ stage 2 , aortal regurgitation. All clinical investigations were conducted according to the declaration of helsinki principles. Ethical consent for this study has been given by the institutional committee on human research and is compliant with ethical standards on human experimentation and with the helsinki declaration.

\subsection{Materials}

Phosphate buffer with $\mathrm{pH}=7.4, \mathrm{c}=0.3 \mathrm{~mol} / \mathrm{l}$ was prepared from potassium dihydrogen phosphate $\left(\mathrm{KH}_{2} \mathrm{PO}_{4}\right)$ and dipotassium hydrogen phosphate $\left(\mathrm{K}_{2} \mathrm{HPO}_{4}\right)$ which were purchased from Fluka AG, Switzerland and deionized water.

\subsection{Methods}

\subsubsection{Synchronous Fluorescence Fingerprint of Blood Serum}

The samples of blood serum of the patients $(n=50)$ and healthy subjects $(n=10)$ were diluted $(1: 10000)$ in the phosphate buffer $(\mathrm{pH}=7.4)$ immediately before the measurement. The intensity of autofluorescence of the individual control and the experimental samples was measured in a quartz cuvette ( $1 \mathrm{~cm}$ width; $2.5 \mathrm{ml}$ volume) by synchronous fluorescence fingerprint (SFF) analysis on Perkin-Elmer Luminiscence Spectrophotometer LS 55, $\mathrm{t}=25^{\circ} \mathrm{C}$. Excitation spectra were measured in the wavelength range $\lambda_{e x}=$ 200 - $390 \mathrm{~nm}, \Delta 10$. The rate of scans was $800 \mathrm{~nm} / \mathrm{s}$, the setting of instrument's excitation slit was $5 \mathrm{~nm}$ and emission slit was $5 \mathrm{~nm}$. The measurement of each sample was repeated 10 times. The measured results of fluorescence spectra were processed using the graphic WinLab software (version 4, 2001). The resulting three-dimensional spectrum of the SFF was created 10 simple synchronous scan spectra of blood serum measured at various $\Delta \lambda$ located in the area with the increment 10 [15]. The measured spectra 
were used for the study of dynamics of ischemia heart disease in blood serum by comparing them with the control spectrum of the healthy subjects. Measurement of total fluorescence by synchronous fluorescence fingerprint is increasingly used in the analysis of a mixture of unknown samples because it provides more information about the mixture in contrast to simple synchronous fluorescence excitation spectra [16].

\subsubsection{Atomic Force Microscopy}

Exogenous structure of blood serum layers deposited on the glass slides were studied by atomic force microscopy (AFM). Blood serum of the patients and healthy subjects was prepared by pipetting a droplet of $5 \mu \mathrm{l}$ on the specially cleaned slides (ultrasound, special nanopaper). Subsequently, blood serum was stretched over the surface of the microscopic slide by the method of the blood smear and dried at the room temperature without fixation. The samples were analyzed using atomic force microscope Dimension Icon (model FastScan, Bruker). Each surface of the analyzed samples was processed into graphic form by ScanAsyst ${ }^{\text {tm }}$ software.

\subsubsection{Statistical Analysis}

The fluorescence intensities (for ten repetitions) of the patient's blood serum were statistically compared to the control group of blood serum of the healthy subjects using both one-way analysis of variance (ANOVA) and Tukey-Kramer test at significance level, $\left.\mathrm{p}<0.001{ }^{* * *}\right)$.

\section{Results and Discussion}

\subsection{Synchronous Fluorescence Fingerprint of Blood Serum}

Graphical comparison of the 3-D maps (Figure 1) and the contour maps (Figure 2, Figure 3) of synchronous fluorescence fingerprint (SFF) of blood serum of healthy subjects is a profile with a characteristic shape differing from patients with heart ischemia. Blood serum of the control healthy subjects shows the fluorescence peak $(\lambda=280$ $\mathrm{nm}$ ) with the fluorescence intensity $\mathrm{F}=354$. Our results showed decreased intensity of fluorescence of blood serum of all patients with heart ischemia in comparison with control blood serum. The blood serum of patients with arterial hypertension stage 3 exhibits the similar intensity of fluorescence, structure and shape of SFF than patients after infarct non ST elevation myocardial infarction (NSTEMI) and patients with angina pectoris. Blood serum of the patients with unstable angina shows the fluorescence peak $(\lambda=280 \mathrm{~nm})$ with lower fluorescence intensity in blood serum $(\mathrm{F}=128)$ in comparison with blood serum of control healthy subjects $(\mathrm{F}=354)$.

Blood serum of the patients with ischemic heart disease shows the fluorescence peak $(\lambda=280 \mathrm{~nm})$ with lower fluorescence intensity in blood serum $(\mathrm{F}=157)$ in comparison with blood serum of control healthy subjects $(F=354)$. Blood serum of the patients with arterial hypertension stage 3 shows the fluorescence peak $(\lambda=280 \mathrm{~nm})$ with lower fluorescence intensity in blood serum $(\mathrm{F}=141)$ in comparison with blood serum of control healthy subjects $(\mathrm{F}=354)$. Blood serum of the patients with high risk of arterial 

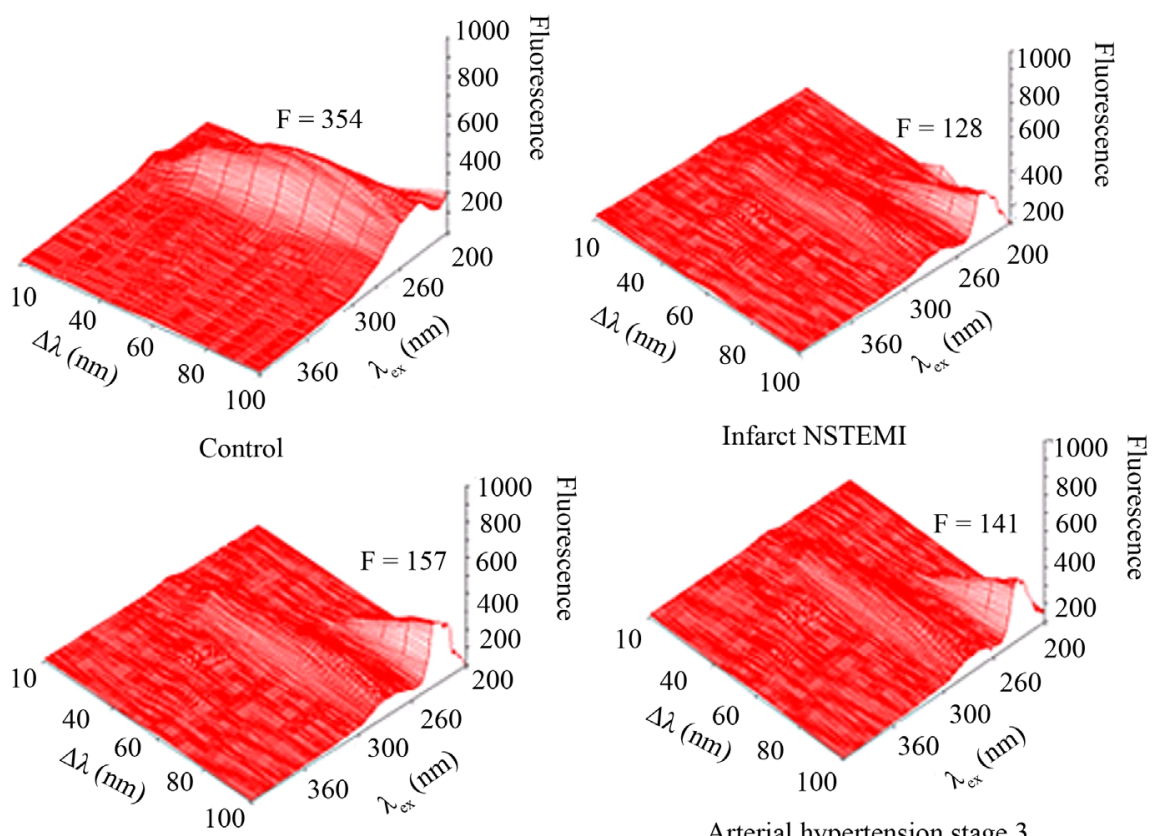

Angina pectoris

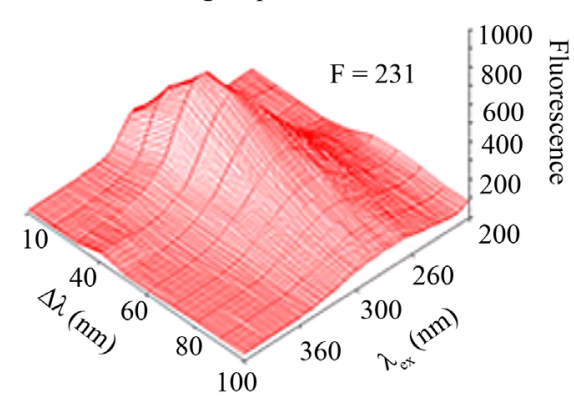

High risk of arterial hypertension stage 2

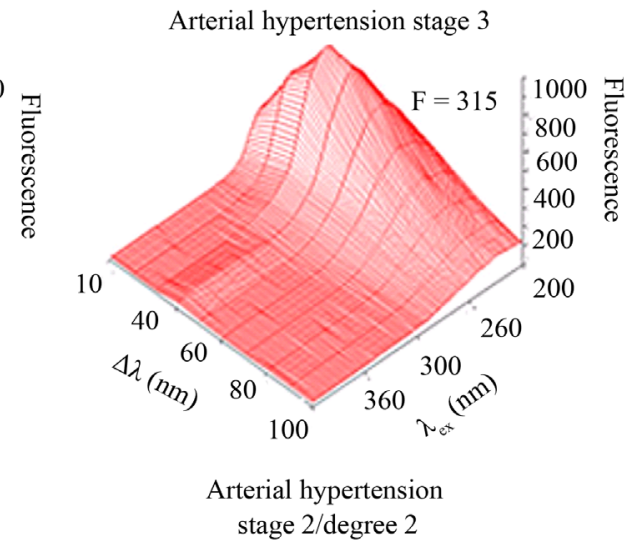

Figure 1. The 3-D maps of fluorescence synchronous fingerpint (SFF) of blood serum of the healthy subject (control) and the selected patients with ischemic heart disease. The fluorescence intensity of fluorescence peak placed at $\lambda=280 \mathrm{~nm} / \Delta \lambda=60 \mathrm{~nm}$ in blood serum was studied in blood serum. The appearance of the new fluorescent peak in blood serum placed at $\lambda=275$ $\mathrm{nm} / \Delta \lambda=30 \mathrm{~nm}$ with the fluorescence intensity $\mathrm{F}=482$ (left) $\mathrm{F}=700$ (right) is observed in blood serum of patients with arterial hypertension stage.

hypertension stage 2 shows the fluorescence peak $(\lambda=280 \mathrm{~nm})$ with lower fluorescence intensity in blood serum $(\mathrm{F}=231)$ in comparison with blood serum of control healthy subjects $(\mathrm{F}=354)$. There is an appearance of the new fluorescent peak in blood serum placed at $\lambda=275 \mathrm{~nm} / \Delta \lambda=30 \mathrm{~nm}$ with the fluorescence intensity $\mathrm{F}=482$ (case 4 ) which is not present in blood serum of control healthy subjects. Blood serum of the patients with arterial hypertension stage 2 /degree 2, aortal regurgitation (case 5) shows the fluorescence peak $(\lambda=280 \mathrm{~nm})$ with lower fluorescence intensity in blood serum ( $\mathrm{F}=$ $315)$ in comparison with blood serum of control healthy subjects $(\mathrm{F}=354)$. In this case, there is also the appearance of the new fluorescent peak in blood serum placed at $\lambda=$ $275 \mathrm{~nm} / \Delta \lambda=30 \mathrm{~nm}$ with the fluorescence intensity $\mathrm{F}=700$. 

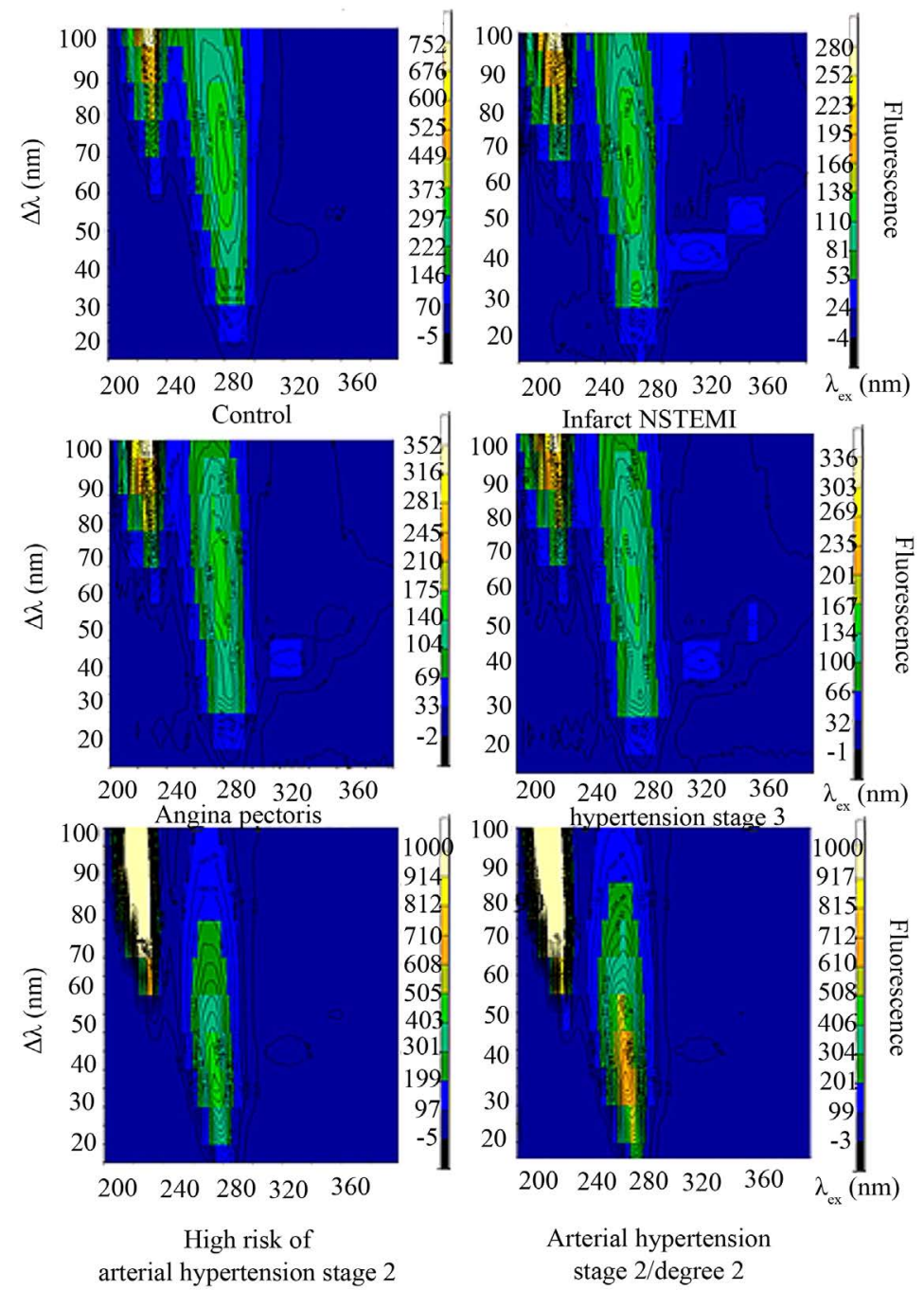

Figure 2. The contour maps of SFF of individual blood serum of the healthy subject (control) and the patients with ischemic heart disease. The fluorescence intensity of fluorescence peak placed at $\lambda=280 \mathrm{~nm} / \Delta \lambda=60 \mathrm{~nm}$ in blood serum was studied in blood serum. The appearance of the new fluorescent peak in blood serum placed at $\lambda=275 \mathrm{~nm} / \Delta \lambda=30 \mathrm{~nm}$ with the fluorescence intensity $\mathrm{F}=482$ (left) $\mathrm{F}=700$ (right) is observed in blood serum of patients with arterial hypertension stage 2 .

Statistical analysis of average fluorescence intensity in blood serum of patients with several cases of heart ischemia (Figure 4) revealed significant decrease of fluorescence intensity in patients in comparison with healthy subjects.

Synchronous fluorescence fingerprint studied different biological fluids and tissues for example during tracking oxidation of lipoproteins in the blood serum in relation to atherosclerosis and cancer [17]. Blood serum sensitively reveals changes in the body, thus becomes the object of an appropriate examination by using untraditional novel techniques of synchronous fluorescence fingerprint. Synchronous fluorescence spectrum defines the mixture of blood serum and is considered to be a characteristic "fingerprint" as it is specific for a given blood serum suspension of the control healthy subjects. This 

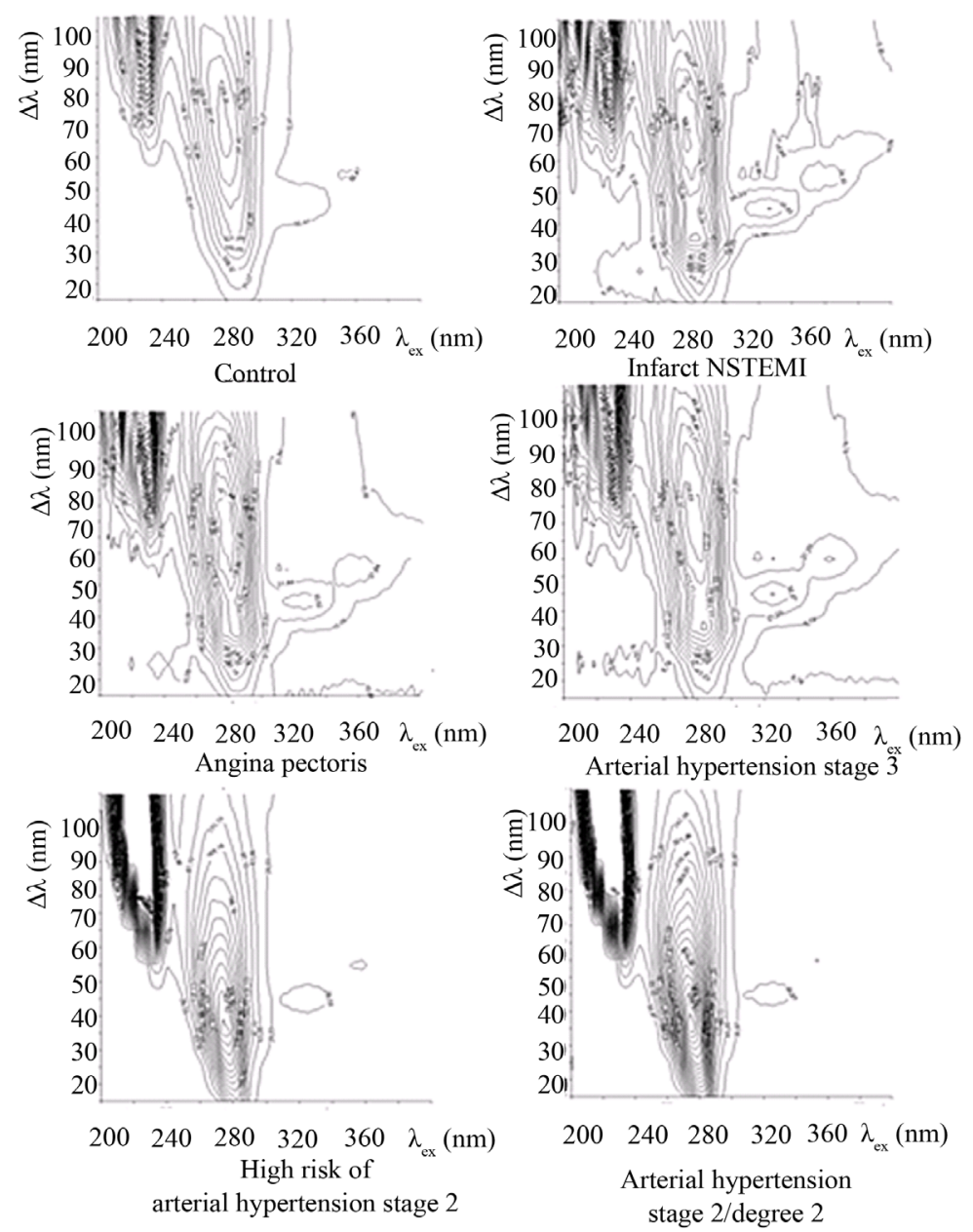

Figure 3. The contour maps of SFF of individual blood serum of the healthy subject (control) and the patients with ischemic heart disease. The fluorescence intensity of fluorescence peak placed at $\lambda=280 \mathrm{~nm} / \Delta \lambda=60 \mathrm{~nm}$ in blood serum was studied in blood serum. The appearance of the new fluorescent peak in blood serum placed at $\lambda=275 \mathrm{~nm} / \Delta \lambda=30 \mathrm{~nm}$ with the fluorescence intensity $\mathrm{F}=482$ (left) $\mathrm{F}=700$ (right) is observed in blood serum of patients with arterial hypertension stage 2 .

method also enables the analysis of the multifluorescent mixture of blood serum and its dynamic changes during acute myocardial infarction. A detailed analysis of the fluorescence curve is not essential for the diagnosis. The qualitative and quantitative change of the individual components in blood serum mixture has a large informative value. This change occurs in characteristically designated fluorescence intense areas at specific wavelengths of fluorescence spectrum [16]-[19]. A simple comparison of results can confirm or disprove the identity of the two mixtures of blood serum during different diseases. Changes of fluorophores under endogenous or exogenous stress factors in patients with heart ischemia disrupt balance of mutual interactions of fluorophores in blood serum. Result of ischemia heart disease is modified graphical display exhibiting in SFF as disappearance or formation of the new peak in fluorescence area) with changed total intensity of fluorescence. The formation of the new peak at SFF with 


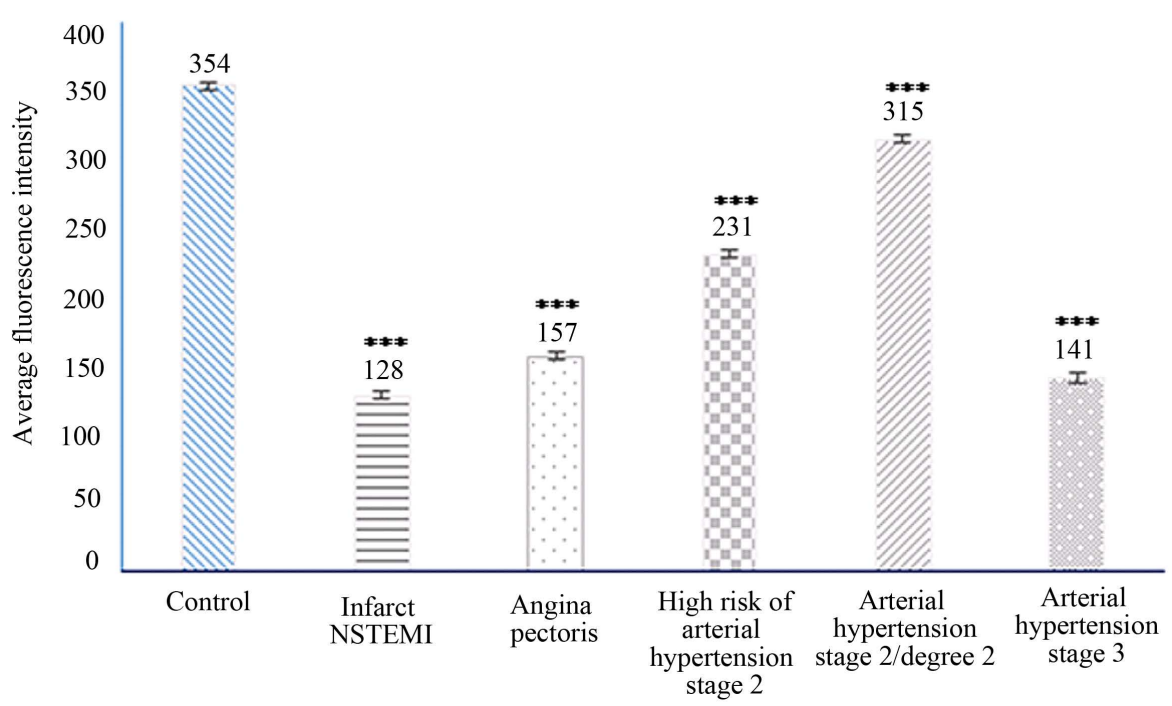

Figure 4. Statistical analysis of average fluorescence intensity in blood serum of patients with heart ischemia.

maximum fluorescence intensity at $\lambda=275 \mathrm{~nm} / \Delta \lambda=30 \mathrm{~nm}$ was observed in blood serum of patients with arterial hypertension stage 2 [16] [18] [19]. Fluorescence profiles of SFF of blood serum of the healthy subject and the patients with heart ischemia in relation to the particular physiological or pathological changes show quantitative and qualitative information about changes of the blood serum structure and characteristics for diagnostic assessment that could be used to inexpensive, sensitive, accurate and rapid screening of heart ischemic diseases [17] [20]. Fluorescence spectroscopy have not been used yet for research of blood serum dynamics during various heart ischemia but could be a new possibility in early diagnosis of heart [16] and other diseases [17] [21].

\subsection{Atomic Force Microscopy of the Blood Serum}

The dynamic changes of surface structure of blood serum in healthy subjects and in the patients using atomic force microscopy (AFM) showed regular globules with width 173 $\mathrm{nm}$, height $2.8 \mathrm{~nm}$ and root mean square (rms) roughness $1.32 \mathrm{~nm}$ (Figure 5).

The surface morphology of blood serum of the patients with unstable angina shows size of the individual globular particles which differs in the higher width $(252 \mathrm{~nm})$, height $(4.0 \mathrm{~nm})$ and $\mathrm{rms}$ roughness $(2.6 \mathrm{~nm})$ in comparison with control blood serum (Figure 5). The patients with angina pectoris shows the individual globular particles with size: width $(493 \mathrm{~nm})$, height $(19.3 \mathrm{~nm})$ and $\mathrm{rms}$ roughness $(6.17 \mathrm{~nm})$. The patients with arterial hypertension stage 3 shows size of the individual globular particles: width $(305 \mathrm{~nm})$, height $(6.9 \mathrm{~nm})$ and rms roughness $(2.58 \mathrm{~nm})$. The patients with high risk of arterial hypertension stage 2 shows size of the individual globular particles: width (263 $\mathrm{nm})$, height $(4.1 \mathrm{~nm})$ and $\mathrm{rms}$ roughness $(1.63 \mathrm{~nm})$. The patients with arterial hypertension stage 2 /degree 2, aortal regurgitation shows size of the individual globular particles: width $(303 \mathrm{~nm})$, height $(6.4 \mathrm{~nm})$ and $\mathrm{rms}$ roughness $(2.93 \mathrm{~nm})$. The blood serum of patients with high risk of arterial hypertension stage 2 exhibits the similar atomic 

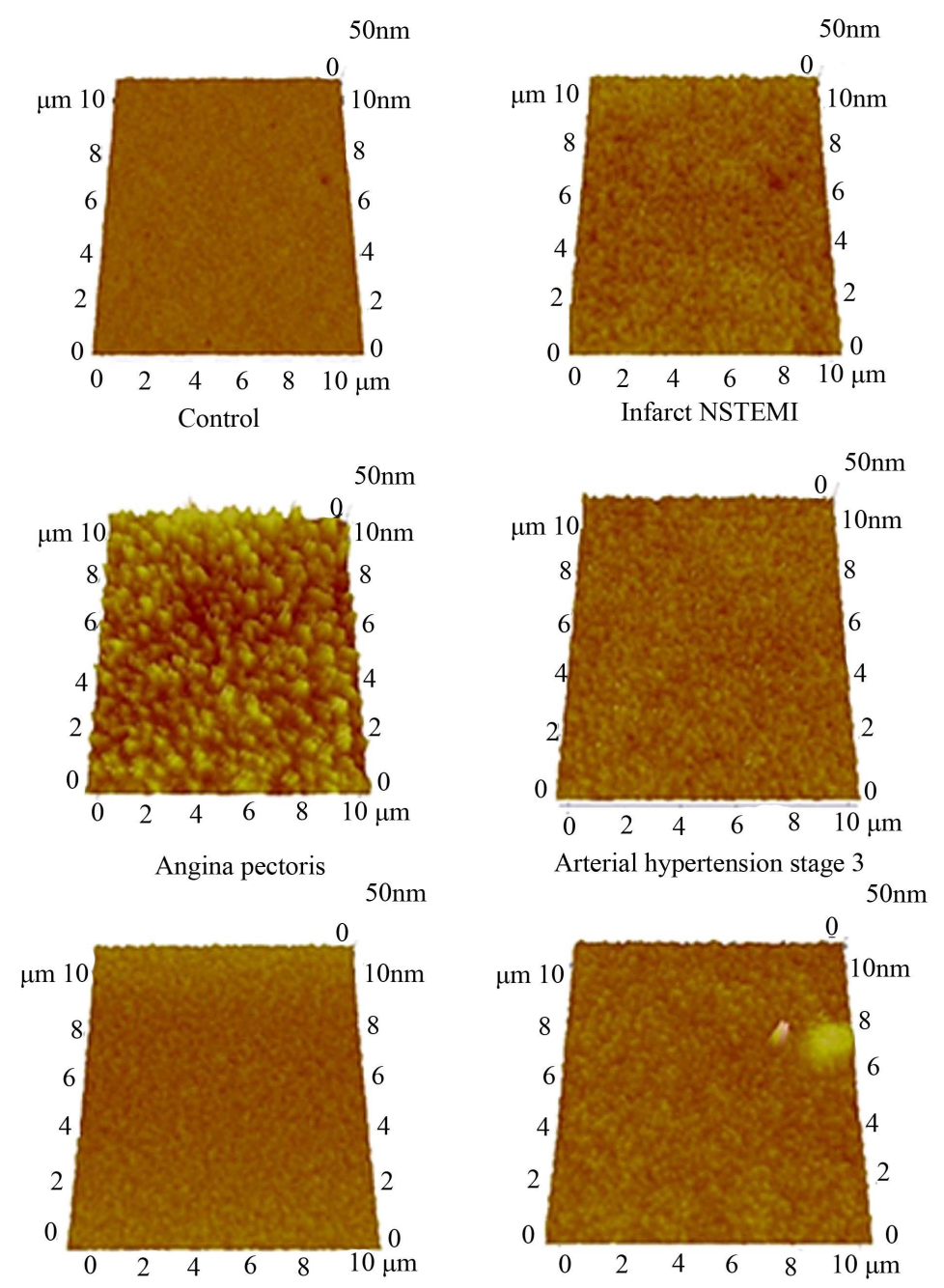

High risk of arterial hypertension stage 2

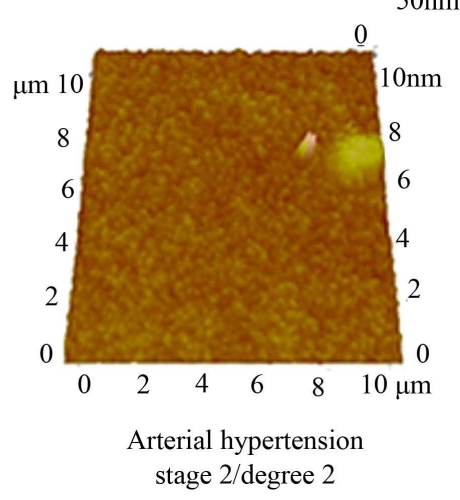

Figure 5. The atomic force microscopy (AFM) of dynamic changes of blood serum of the selected patients with ischemic heart disease in comparison with control blood serum.

microscopic structure than the blood serum of patients with unstable angina NSTEMI. The most changed atomic microscopic structure of blood serum showed the patients with angina pectoris (Figure 5). Average size of globules was calculated from 10 different AFM surface profiles. The representative surface profiles of measured samples are shown in Figure 6.

The AFM images of glass slides have rms roughness $0.5 \mathrm{~nm}$, the slides are significantly smoother than rest of the samples, so overall surface morphology of blood serum samples is not notably influenced. The surface morphology of blood serum of the patients with ischemia heart disease showed different irregular globular proteins. Distribution of globules (Figure 7) shows average heights and widths of globular structures present in AFM images. All samples of blood serums from patients with ischemia heart disease showed significantly different AFM image than control sample. Results demon- 


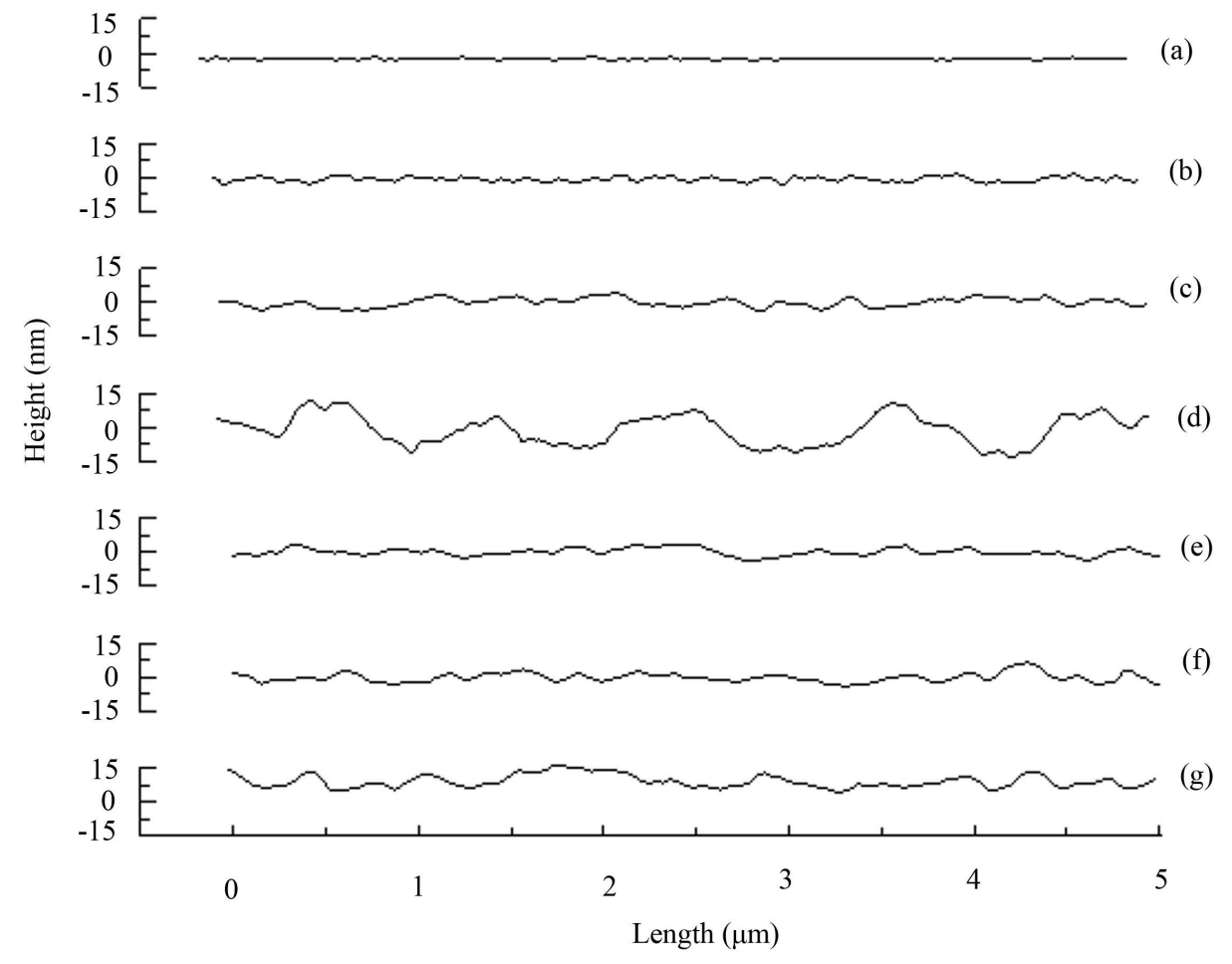

Figure 6. Selected AFM surface profiles of (a) glass slide, (b) control, (c) infarct NSTEMI, (d) angina pectoris, (e) high risk of arterial hypertension stage 2, (f) arterial hypertension stage 2/degree 2, (g) arterial hypertension stage 3.

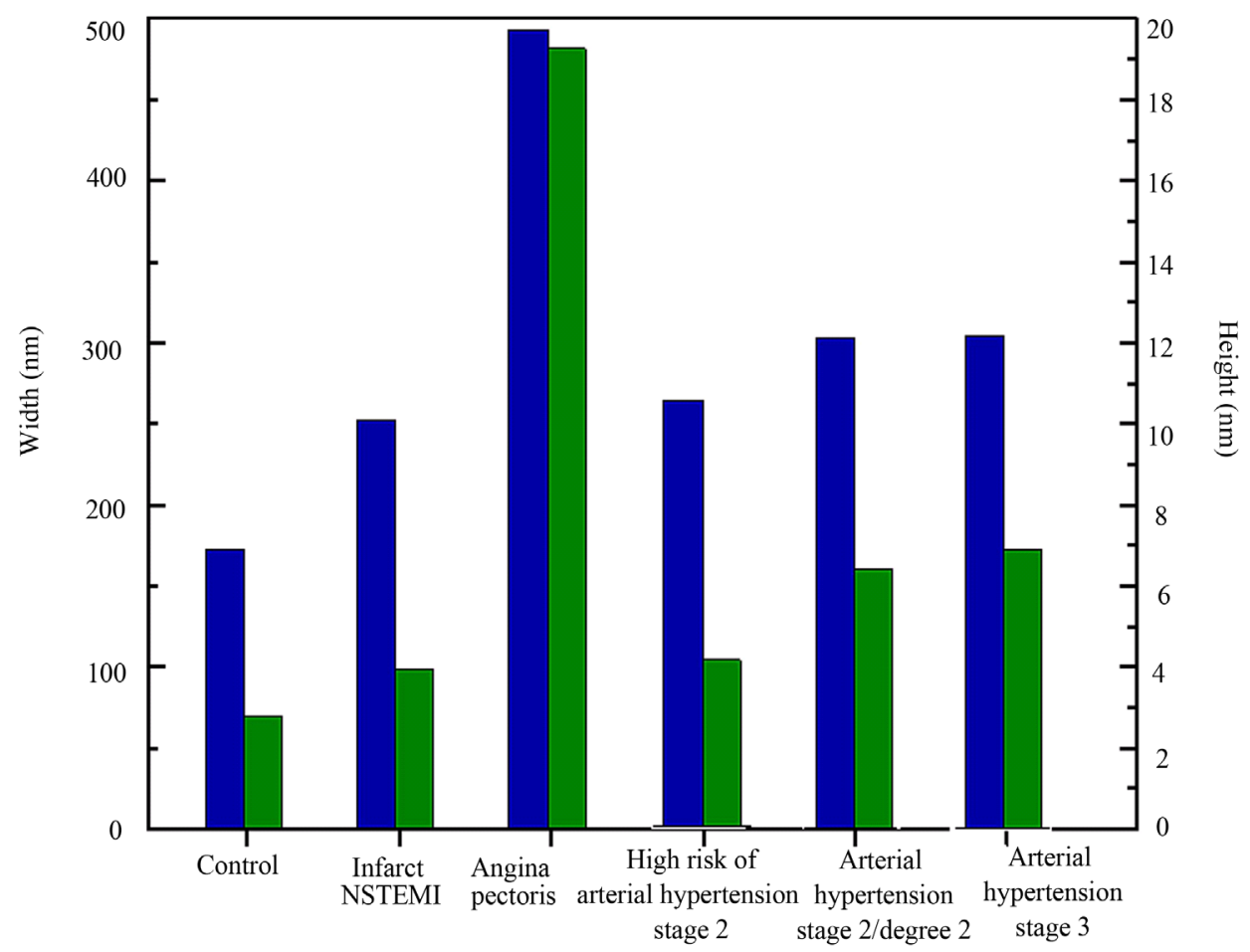

Figure 7. Distribution of globules with average widths and heights of globular structures present in AFM images (blue columns indicate widths, green columns indicate height). 
strate the diagnostic potential of atomic force microscopy in a wide range of applications in the early diagnosis of heart diseases [16] [19].

\section{Conclusion}

This study was investigated blood serum of the patients with ischemic heart disease in comparison with control blood serum of the healthy subject using synchronous fluorescence fingerprint and atomic force microscopy. The total fluorescence intensity of blood serum of the individual cases changed. The blood serum of patients with arterial hypertension stage 3 exhibits the similar intensity of fluorescence of SFF than patients with NSTEMI and patients with angina pectoris. Patients with arterial hypertension stage 2 showed the formation of the new peak at SFF with maximum fluorescence intensity. Atomic force microscopy of blood serum showed the arranged structure of the globules in the healthy subjects. However, the structure of the globules in the patients with heart ischemia reflected disordered and enlarged globules with the increased roughness of the surface. The patients with the disease combined with angina pectoris showed the greatest change of the blood surface. These methods enable the analysis of blood serum and might be a new possibility in the study of heart ischemia diseases. This research demonstrates the possibility of analysis of ischemia heart disease by fluorescence technique and atomic force microscopy using minimum amount of blood serum. These unconventional methods could contribute to the early differential diagnosis of a variety of cardiovascular diseases.

\section{Acknowledgements}

This work was supported by the Slovak Grant Agency for Science under the contract VEGA-1/0115/14 and VEGA-1/0409/15.

\section{References}

[1] White, H.D. and Chew, D.P. (2008) Acute Myocardial Infarction. Lancet, 372, 570-584. http://dx.doi.org/10.1016/S0140-6736(08)61237-4

[2] O'Gara, P.T., et al. (2013) 2013 ACCF/AHA Guideline for the Management of ST-Elevation Myocardial Infarction: A Report of the American College of Cardiology Foundation/ American Heart Association Task Force on Practice Guidelines. Circulation, 127, 362-425. http://dx.doi.org/10.1161/CIR.0b013e3182742c84

[3] Opie, L.H. (1975) Metabolism of Free Fatty Acids, Glucose and Catecholamines in Acute Myocardial Infarction: Relation to Myocardial Ischemia and Infarct Size. The American Journal of Cardiology, 36, 938-953. http://dx.doi.org/10.1016/0002-9149(75)90086-7

[4] Bodi, V., et al. (2012) Metabolomic Profile of Human Myocardial Ischemia by Nuclear Magnetic Resonance Spectroscopy of Peripheral Blood Serum: A Translational Study Based on Transient Coronary Occlusion Models. Journal of the American College of Cardiology, 59, 1629-1641. http://dx.doi.org/10.1016/j.jacc.2011.09.083

[5] Flierl, M.A., Rittirsch, D., Huber-Lang, M., Sarma, J.V. and Ward, P.A. (2008) Catecholamines-Crafty Weapons in the Inflammatory Arsenal of Immune/Inflammatory Cells or Opening Pandora's Box? Molecular Medicine, 14, 195. 
[6] Wannemacher, R.W., Klainer, A.S., Dinterman, R.E. and Beisel, W.R. (1976) The Significance and Mechanism of an Increased Serum Phenylalanine-Tyrosine Ratio during Infection. The American Journal of Clinical Nutrition, 29, 997-1006.

[7] Guleria, A., et al. (2015) NMR-Based Serum Metabolomics Discriminates Takayasu Arteritis from Healthy Individuals: A Proof-of-Principle Study. Journal of Proteome Research, 14, 3372. http://dx.doi.org/10.1021/acs.jproteome.5b00422

[8] Sun, L., et al. (2012) Metabonomics Reveals Plasma Metabolic Changes and Inflammatory Marker in Polycystic Ovary Syndrome Patients. Journal of proteome research, 11, 29372946. http://dx.doi.org/10.1021/pr3000317

[9] Deidda, M., et al. (2015) Metabolomic Approach to Profile Functional and Metabolic Changes in Heart Failure. Journal of Translational Medicine, 13, 297. http://dx.doi.org/10.1186/s12967-015-0661-3

[10] Zhong, X., et al. (2012) Glycine Attenuates Myocardial Ischemia-Çôreperfusion Injury by Inhibiting Myocardial Apoptosis in Rats. Journal of Biomedical Research, 26, 346-354. http://dx.doi.org/10.7555/JBR.26.20110124

[11] Drake, K.J., Sidorov, V.Y., McGuinness, O.P., Wasserman, D.H. and Wikswo, J.P. (2012) Amino Acids as Metabolic Substrates during Cardiac Ischemia. Experimental Biology and Medicine, 237, 1369-1378. http://dx.doi.org/10.1258/ebm.2012.012025

[12] Ouyang, X., Dai, Y., Wen, J.L. and Wang, L.X. (2011) (1)H NMR-Based Metabolomic Study of Metabolic Profiling for Systemic Lupus Erythematosus. Lupus, 20, 1411. http://dx.doi.org/10.1177/0961203311418707

[13] Filippo, C.D., Cuzzocrea, S., Rossi, F., Marfella, R. and D’Amico, M. (2006) Oxidative Stress as the Leading Cause of Acute Myocardial Infarction in Diabetics. Cardiovascular Drug Reviews, 24, 77-87. http://dx.doi.org/10.1111/j.1527-3466.2006.00077.x

[14] Keller, J.N. (2006) Interplay between Oxidative Damage, Protein Synthesis, and Protein Degradation in Alzheimer's Disease. BioMed Research International, 2006, 12129.

[15] Berezin, M.Y. and Achilefu, S. (2010) Fluorescence Lifetime Measurements and Biological Imaging. Chemical Reviews, 110, 2641-2684. http://dx.doi.org/10.1021/cr900343z

[16] Tomečková, V., Bohó, A., Komanický V., Tomečko, M. and Gulašová, Z. (2015) Monitorovanie rôznych srdcových ochorení z autofluorescencie krvi. Ateroskleróza, 19, 694.

[17] Zhang X. Fales A. and Vo-Dinh, T. (2015) Time-Resolved Synchronous Fluorescence for Biomedical Diagnosis. Sensors, 15, 21746-21759. http://dx.doi.org/10.3390/s150921746

[18] Bohó, A., Tomečková, V. and Sedláková, E. (2012) Využitie fluorescenčnej analýzy pri včasnej diagnostike akútneho koronárneho syndrómu. Cardiology Letters, 21, 124-130.

[19] Gulašová, Z., et al. (2015) Monitoring of Thoracic Aortic Aneurysm in Blood by Fluorescence Spectroscopy. American Journal of Medical and Biological Research, 3, 128-132. http://dx.doi.org/10.12691/ajmbr-3-5-2

[20] Zhu, W., Zhao, Z., Guo, X. and Hong, X. (2010) Study on Serum Fluorescence Spectra Based on Wavelet Transform. African Journal of Biotechnology, 9, 892-899. http://dx.doi.org/10.5897/AJB09.1412

[21] Masilamani, V., et al. (2012) Fluorescence Spectra of Blood and Urine for Cervical Cancer Detection. Journal of Biomedical Optics, 17, 098001.

http://dx.doi.org/10.1117/1.jbo.17.9.098001 
Submit or recommend next manuscript to SCIRP and we will provide best service for you:

Accepting pre-submission inquiries through Email, Facebook, LinkedIn, Twitter, etc. A wide selection of journals (inclusive of 9 subjects, more than 200 journals)

Providing 24-hour high-quality service

User-friendly online submission system

Fair and swift peer-review system

Efficient typesetting and proofreading procedure

Display of the result of downloads and visits, as well as the number of cited articles

Maximum dissemination of your research work

Submit your manuscript at: http://papersubmission.scirp.org/ 